\title{
Fluoroquinolone-resistant Salmonella typhi infection: a report of two cases in South Africa
}

\author{
${ }^{a}$ School of Pharmacy, Sefako Makgatho Health Sciences University, Pretoria, South Africa \\ ${ }^{b}$ The Ohio State University Wexner Medical Center, Columbus, OH, USA \\ 'Department of Microbiology, Sefako Makgatho Health Sciences University, Pretoria, South Africa \\ ${ }^{d}$ Dr George Mukhari Academic Hospital, Ga-Rankuwa, South Africa \\ *Corresponding author, email: natalie.schellack@smu.ac.za
}

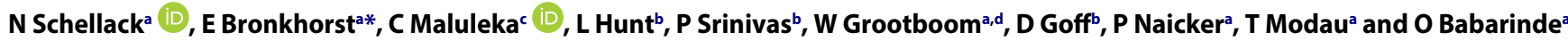

Typhoid and paratyphoid fever are acute, life-threatening febrile illnesses caused by systemic infection with the bacterium Salmonella enterica. Nineteen cases were reported in South Africa in 2016. We report on two cases of bacteraemic invasive $S$. typhi with fluoroquinolone resistance.

Keywords: multi-drug resistant, quinolone resistance, Salmonella typhi, S. typhi, typhoid

\begin{abstract}
Introduction
Typhoid and paratyphoid are important global public health concerns as they are major causes of morbidity in the developing world. ${ }^{1}$ Typhoid and paratyphoid fever are acute and often lifethreatening febrile illnesses caused by the enteric Gram-negative bacillus, Salmonella enterica, serotype typhi and paratyphi. The species $S$. enterica contains more than 2500 serotypes. However, less than 100 serotypes are responsible for human infections, particularly S. typhi, and S. paratyphi A and B.,3
\end{abstract}

The mainstay of treatment of typhoid in most parts of the world involves the use of fluoroquinolones owing to resistance to previous first-line agents, such as ampicillin and trimethoprimsulfamethoxazole (TMP-SMX). Multidrug-resistant (MDR) and fluoroquinolone-resistant strains have been reported in parts of Asia, and central and sub-Saharan Africa. Typhoid fever remains endemic in some parts in South Africa. However, it is relatively uncommon in most urbanised areas, with only occasional outbreaks. Infection with quinolone-resistant S. typhi in subSaharan Africa and South Africa is limited to case reports. A 5\% prevalence of nalidixic acid-resistant isolates with reduced susceptibility to ciprofloxacin was reported in a recent survey of infections due to quinolone-resistant S. typhi of South Africa between 2003 and 2007. ${ }^{4}$ Hence, fluoroquinolones remain the empiric agent of choice for typhoid in Africa.

Case reports of two patients with invasive S. typhi infection with varying degrees of resistance to fluoroquinolones will be presented. These cases presented to $\mathrm{Dr}$ George Mukhari Academic Hospital (DGMAH), a 1650 -bed public sector hospital in Pretoria, Gauteng province, South Africa. Informed consent was obtained from the patients and/or family members.

\section{Case study 1: Disseminated intravascular coagulopathy and renal failure in a patient who cultured positive for typhoid}

History: The first case involved a 22-year-old woman who is originally from Mozambique, married and living with her husband and two children in Pretoria. She had no recent travel history, but it was suspected that she had had a visitor from Mozambique. She visited a local clinic in January 2016 owing to persisting vaginal bleeding with blood clots. She was referred to DGMAH two days later with a history of loss of appetite, fatigue (for three days), lethargy and abdominal tenderness.

Examination and investigations: The patient presented with haematemesis and melena stools. She had a brownish vaginal discharge and her cervix was dilated.

This patient was confirmed to be eight weeks pregnant and was human immunodeficiency virus (HIV) negative.

On admission, she presented with a temperature of $38.3^{\circ} \mathrm{C}$, blood pressure (BP) of 109/65 $\mathrm{mm} \mathrm{Hg}$, a pulse of 127 beats per minute (bpm) and respiratory rate of 20 breaths per minute.

A blood culture taken two days after admission grew S. typhi, with a susceptibility profile of TMP-SMX (susceptible ["S"]), ampicillin (S), cefotaxime-ceftriaxone (S) and ciprofloxacin (intermediate ["I"]; MIC $\geq 1$ ).

The abnormal laboratory values are depicted in Table 1, to explain the unstable condition of the patient, for the purposes of the case study.

A primary diagnosis of septic abortion, typhoid fever, with severe epistaxis complicated by disseminated intravascular coagulopathy (DIC) and resulting kidney failure, was made. The patient was initiated on haemodialysis, and received fresh frozen plasma and platelets.

The empirically prescribed antimicrobial treatment was a combination of cefuroxime $250 \mathrm{mg}$ qid, metronidazole $500 \mathrm{mg}$ tds and gentamicin $240 \mathrm{mg}$ daily. Other symptoms, like fever and diarrhoea, were treated with paracetamol and loperamide, respectively. The patient was initiated on TMP/SMX on day five. However, owing to a serum creatinine of $8.7 \mathrm{mg} / \mathrm{dl}$ and the need for haemodialysis, TMP-SMX use was contraindicated in this patient and therapy was changed to ciprofloxacin on day 8. Due to the intermediate susceptibility of the S. typhi isolate to ciprofloxacin, the pharmacist recommended a change of therapy, and therapy was modified to ceftriaxone on day 9. Lansoprazole, 
Table 1: Laboratory results

\begin{tabular}{|c|c|c|}
\hline Item & Reference range & Results \\
\hline Sodium & $135-145 \mathrm{mmol} / \mathrm{l}$ & $130 \mathrm{mmol} / \mathrm{l}$ \\
\hline Potassium & $3.5-5.0 \mathrm{mmol} / \mathrm{l}$ & $2.3 \mathrm{mmol} / \mathrm{l}$ \\
\hline Urea & $2.5-6.5 \mathrm{mmol} / \mathrm{l}$ & $41.1 \mathrm{mmol} / \mathrm{l}$ \\
\hline Serum creatinine & $60-120 \mu \mathrm{mol} / \mathrm{l}$ & $985 \mu \mathrm{mol} / \mathrm{l}$ \\
\hline AST & $5-40 \mathrm{U} / \mathrm{l}$ & $102 \mathrm{U} / \mathrm{I}$ \\
\hline GGT & $5-50 \mathrm{U} / \mathrm{I}$ & $136 \mathrm{U} / \mathrm{I}$ \\
\hline $\mathrm{LDH}$ & $135-225 \mathrm{U} / \mathrm{I}$ & $1086 \mathrm{U} / \mathrm{I}$ \\
\hline RCC & $4.0-5.0 \times 10^{12} / 1$ & $3.02 \times 10^{12} / 1$ \\
\hline Haemoglobin & $12.0-15.0 \mathrm{~g} / \mathrm{dl}$ & $8.8 \mathrm{~g} / \mathrm{dl}$ \\
\hline Haematocrit & $36-44 \%$ & $2.6 \%$ \\
\hline Platelet count & $150-400 \times 10^{9} / 1$ & $79 \times 10^{9} / 1$ \\
\hline Prothrombin time & $10-12 s$ & $45.7 \mathrm{~s}$ \\
\hline PTT & $60-70 s$ & $58.5 \mathrm{~s}$ \\
\hline Fibrinogen & $2-4 \mathrm{~g} / \mathrm{dl}$ & $4.1 \mathrm{~g} / \mathrm{dl}$ \\
\hline D-Dimer & $<0.5 \mu \mathrm{g} / \mathrm{ml}$ & $0.72 \mu \mathrm{g} / \mathrm{ml}$ \\
\hline
\end{tabular}

*AST: aspartate aminotransferase, GGT: gamma-glutamyl transferase, LDH: lactate dehydrogenase, PTT: partial thromboplastin time, RCC: reticulocyte cell count.

levonorgestrel-ethinyl estradiol, vitamin $\mathrm{K}$ and tranexamic acid were prescribed on day 10 to control excessive bleeding.

The patient demised on day 11 due to excessive bleeding and end organ failure.

\section{Case study 2: Salmonella typhi with confusion}

History: A 29-year-old female patient was admitted to the Internal Medicine Department at DGMAH in January 2016. She was referred by a local physician having complained of confusion, lack of sleep and fever spikes for the previous four days. She was the mother of a nine-month-old infant, and had travelled to Zimbabwe two weeks prior to admission.

Examination and investigations: On examination, the patient was fully conscious, but was in an acute confused state, with memory impairment and mild dehydration. She had a history of postpartum hypertension, but was not on any medication and her HIV status was unknown. Her vital signs were temperature of $38.7^{\circ} \mathrm{C}$, BP of $176 / 107 \mathrm{~mm} \mathrm{Hg}$, pulse of $121 \mathrm{bpm}$, HGT of $5.4 \mathrm{mmol} / \mathrm{l}$ and oxygen saturation of $95 \%$. She weighed $80 \mathrm{~kg}$.

The patient was provisionally diagnosed with cerebral malaria and bacterial meningitis, but both were ruled out after the cerebrospinal fluid tests were performed and the malaria screening was negative. A blood culture was requested, and the following results, confirming typhoid fever, were obtained from microbiology: the Gram stain indicated Gram-negative bacilli, which was later identified as S. typhi, with the following susceptibility profile: TMP-SMX (resistant ["R"]), amoxicillinclavulanic acid (S), cefotaxime-ceftriaxone (S), ampicillinamoxicillin (R) and ciprofloxacin (R); MIC $\geq 1$.

The patient was treated empirically with ceftriaxone intravenously before the susceptibility profile was obtained; paracetamol four times daily and lorazepam intravenously were administered when necessary. Hydrochlorothiazide $12.5 \mathrm{mg}$ was initially prescribed for the patient, but was later increased to $25 \mathrm{mg}$ orally daily, owing to elevated systolic and diastolic BP.
Table 2: Patient's blood results

\begin{tabular}{|l|c|c|}
\hline Item & Reference range & Result \\
\hline Albumin & $35-52 \mathrm{~g} / \mathrm{l}$ & $26 \mathrm{~g} / \mathrm{l}$ \\
\hline Haemoglobin & $11.6-16.4 \mathrm{~g} / \mathrm{dl}$ & $10.4 \mathrm{~g} / \mathrm{dl}$ \\
\hline Direct bilirubin & $0-3$ & 4 \\
\hline Iron & $9.0-30.4 \mu \mathrm{mol} / \mathrm{l}$ & $7.3 \mu \mathrm{mol} / \mathrm{l}$ \\
\hline Transferrin & $2.50-3.80 \mathrm{~g} / \mathrm{l}$ & $1.5 \mathrm{~g} / \mathrm{l}$ \\
\hline Ferritin & $15-160 \mu \mathrm{g} / \mathrm{l}$ & $1674 \mu \mathrm{g} / \mathrm{l}$ \\
\hline LDH & $135-225 \mathrm{U} / \mathrm{l}$ & $654 \mathrm{U} / \mathrm{l}$ \\
\hline GGT & $<40 \mathrm{U} / \mathrm{l}$ & $45 \mathrm{U} / \mathrm{l}$ \\
\hline CRP & $<10 \mathrm{mg} / \mathrm{l}$ & $87 \mathrm{mg} / \mathrm{l}$ \\
\hline
\end{tabular}

*CRP: C-reactive protein, GGT: gamma-glutamyl transferase, LDH: lactate dehydrogenase.

The abnormal laboratory results obtained on day two after admission are depicted in Table 2.

The serum creatinine was calculated to be $164.23 \mathrm{ml} /$ minute/1.73 $\mathrm{m}^{2}$, using the Cockcroft-Gault equation.

The patient improved clinically, the follow-up laboratory results were normal and she was discharged after nine days of treatment.

\section{Discussion}

In 2010, the incidence of typhoid in sub-Saharan Africa was estimated to be $>100$ cases per 100000 persons per year, with more than 30000 deaths, leading to a global estimate of $26 \%$ of typhoid cases occurring in Africa. ${ }^{5}$ A large-scale outbreak involving 1000 cases in Delmas, Mpumalanga, was reported in 1993, due to a contaminated water supply. The National Institute for Communicable Diseases ${ }^{6}$ reported 104 cases in South Africa in 2014, and 76 cases in 2015 of which 15 were non-invasive and 61 invasive. $^{6}$ During 2016, to date of study, a total of 19 cases have been reported across South Africa-10 from Gauteng province, including the two cases seen at DGMAH. Seven of the $19(37 \%)$ reported cases were children aged $\leq 12$ years. ${ }^{3}$

Typhoid is a communicable disease that is transmitted via the faecal-oral route. There are various ways in which this can occur, including the ingestion of food or drinks (handled by an asymptomatic carrier of the bacteria), oral transmission (drinking water contaminated by sewage), the consumption of shellfish (taken from contaminated water), poor hygiene practices (using a contaminated toilet), or the consumption of raw fruit and vegetables (fertilised by sewage contaminated with S. typhi) ${ }^{7,8}$ The origin of infection in the two patients described in this case report could not be established. However, the patients' travel history could be traced back to neighbouring countries. Patient 1 was in contact with a family member from Mozambique, and patient 2 travelled outside the borders of South Africa to Zimbabwe.

By the 1980s, the emergence of MDR strains of S. typhi, demonstrating resistance to first-line agents such as chloramphenicol, ampicillin and TMP-SMX, started to present a major treatment challenge., ${ }^{9,10}$ Hence, fluoroquinolones became the mainstay of treatmentfortyphoid in Africa. ${ }^{11}$ Fluoroquinolones easily penetrate tissue, including the gall bladder, and kill S. typhi in its intracellular stationary phase. Additionally, this class of antibiotics facilitates rapid clearance of the organism, leading to a prompt clinical response, with lower rates of chronic carriage, compared with traditional first-line agents. Fluoroquinolones are 
generally well tolerated and are rapidly effective, even with short courses of treatment. Short courses of 3-5 days of therapy are generally adequate for epidemics. However, 10-14 days of highdose fluoroquinolone, with close monitoring of faecal shedding, may be needed for cases of infection with quinolone-resistant $S$. typhi. ${ }^{10-12}$ Evidence supporting the use of fluoroquinolones in paediatrics has suggested minimal toxicity with both long- and short-term use. ${ }^{10}$

With the increased use of fluoroquinolones to treat MDR typhoid fever, an increase in resistance to ciprofloxacin (minimum inhibitory concentration $\geq 1 \mu \mathrm{g} / \mathrm{ml}$ ) was demonstrated in recent reports, especially in developing countries like India, Southern Asia and sub-Saharan Africa, which have been associated with clinical treatment failure. ${ }^{13}$ Salmonella fluoroquinolone resistance used to be detected by nalidixic acid, a non-fluorinated quinolone, due to its target site mutations in the fluoroquinolone resistance-determining region (QRDR). ${ }^{13}$ However, due to plasmid-mediated quinolone resistance (PMQR), there are QRDR mutations that are still sensitive to nalidixic acid, making it difficult to use nalidixic acid as a marker of fluoroquinolone resistance. ${ }^{14}$ Third-generation cephalosporins, such as ceftriaxone, or azithromycin, are effective alternative agents for the treatment of typhoid in these situations. ${ }^{10-12}$ Oral azithromycin results in defervescence within 4-6 days, with less than $3 \%$ of cases of relapse. Azithromycin is also associated with lower rates of treatment failure and a shorter duration of hospitalisation than those achieved with the fluoroquinolones. ${ }^{13}$ Carbapenems, aztreonam and tigecycline are potential last-line agents to be considered in cases in which full resistance to ciprofloxacin and cephalosporins has been demonstrated. ${ }^{10,12}$

In 1996, Mirza et al. reported that, in general, S. typhi in Africa remained sensitive to one or more of the first-line agents. However, outbreaks of MDR strains have been noted to occur at varying rates throughout central and sub-Saharan Africa, particularly in the Democratic Republic of Congo, Ghana and Kenya, and along the Malawi-Mozambique border. ${ }^{12}$ In South Africa, ciprofloxacin resistance was reported at 50\% prevalence amongst human isolates, resulting in this antimicrobial agent being discouraged as a treatment option. Currently, however, all isolates were azithromycin-susceptible. ${ }^{15}$ The two S. typhi isolates reported here exhibited intermediate to full resistance to ciprofloxacin (MIC $\geq 1$ ), which is of special interest in South Africa as it highlights the spread of MDR strains across borders.

\section{Conclusion}

Our two cases demonstrate the emergence of fluoroquinoloneresistant strains of S. typhi in South Africa as a national and global concern. MDR strains of $S$. typhi exist worldwide. Concerns about the global spread of MDR strains are valid owing to extensive modes of international travel and varying degrees of infection prevention measures, particularly in Third World countries. Broad-spectrum antibiotics, such as ceftriaxone or azithromycin, used to treat fluoroquinolone-resistant S. typhi, can be considered, but should be prescribed in accordance with antimicrobial stewardship guidelines. Overuse of broadspectrum antibiotics may promote antimicrobial resistance in other organisms.
The management of both patients involved collaboration between physicians, the microbiology team and pharmacists in identifying and selecting the most appropriate antimicrobial therapy for the isolated MDR organisms. A multidisciplinary team approach is recommended in the management of typhoid and any other communicable disease.

\section{ORCID}

N Schellack (D) http://orcid.org/0000-0001-9690-6285

C Maluleka iD http://orcid.org/0000-0003-3700-9669

\section{References}

1. Crump JA, Luby SP, Mintz ED. The global burden of typhoid fever. Bull World Health Org. 2004;82:346-53.

2. Moreno Switt Al, Soyer Y, Warnick LD, et al. Foodborne Pathog Dis. 2009;6(4):407-15. https://doi.org/10.1089/fpd.2008.0213

3. Centers for Disease Control and Prevention. Serotypes and the importance of serotyping Salmonella. [cited 2016 Feb 18]. Available from: https://www.cdc.gov/salmonella/reportspubs/salmonellaatlas/serotyping-importance.html

4. Smith AM, Govender N, Keddy KH. Quinolone-resistant salmonella typhi in South Africa, 2003-2007. Epidemiol Infect. 2010;138:86-90. https://doi.org/10.1017/S0950268809990331

5. Mogasale V, Maskery B, Ochiai RL, et al. Burden of typhoid fever in lowincome and middle-income countries: a systematic, literature-based update with risk-factor adjustment. Lan Glob Health. 2014;2:e570e80. https://doi.org/10.1016/S2214-109X(14)70301-8

6. National Institute for communicable Diseases: GERMS South Africa annual report 2014/2015. 2014/2015. [cited 2016 Jan 29]. Available from: https://www.nicd.ac.za/assets/files/GERMS-SA\%20AR\%20 2015-1.pdf

7. Brusch JL, Corales R, Schmitt SK, et al. Typhoid fever. [cited 2016 Jan 29]. Available from: https://emedicine.medscape.com/ article/231135-overview

8. Wain J, Hendriksen RS, Mikoleit ML, et al. Typhoid fever. Lancet. 2015;385(9973):1136-45. PMID: 25458731. Available from: www. ncbi.nlm.nih.gov/pubmed/25458731.

9. Mirza SH, Beechmg NJ, Hart CA. Multi-drug resistant typhoid: A global problem. J Med Microbiol. 1996;44:317-9. https://doi. org/10.1099/00222615-44-5-317

10. Parry CM, Hien TT, Dougan G,et al. Typhoid fever. N Eng J Med 2002;347(22):1770-1782. https://doi.org/10.1056/NEJMra020201

11. Sánchez-Vargas FM, Abu-El-Haija MA, Gómez-Duarte OG. Salmonella infections: An update on epidemiology, management, and prevention. Travel Med Infect Dis 2011;9(6):263-77. https://doi. org/10.1016/j.tmaid.2011.11.001

12. World Health Organization. Background document: The diagnosis, treatment and prevention of typhoid fever. 2003 [cited 2016 July 17]. Available from: https://www.who.int/rpc/TFGuideWHO.pdf

13. Johnston C, Pegues DA, Hueck CJ, et al. Transcriptional activation of Salmonella typhimurium invasion genes by a member of the phosphorylated response-regulator superfamily. Molecular Microbiology 1996 Nov;22(4):715-27. https://doi. org/10.1046/j.1365-2958.1996.d01-1719.x

14. Fang F. Correction for fang, fluoroquinolone resistance in salmonella and the utility of perfloxacin disk diffusion. J Clinic Microbiol 2015;54(1):245.

15. Smith AM, Tau N, Sooka A, Keddy KH. Microbiological characterization of Salmonella enterica serotype Paratyphi, South Africa, 2003-2014. J Med Microbiol. 2015; 64(11):1450-3.

Received: 04-08-2016 Accepted: 18-09-2017 